\title{
Flooding in Oda River Basin during Torrential Rainfall Event in July 2018
}

\author{
Shakti P. C., ${ }^{a, *}$ and Hideyuki Kamimera ${ }^{\mathrm{b}}$ \\ National Research Institute for Earth Science and Disaster Resilience (NIED), Tsukuba, Japan \\ E-mail: ashakti.pc@gmail.com (Corresponding author), bkamimera@bosai.go.jp
}

\begin{abstract}
Extreme rainfall events cause severe flooding and/or landslides almost every summer in Japan. It seems that the frequency of such events and induced human/economic losses has increased in recent years. A torrential rainfall event in early July 2018 caused severe flooding in many river basins over Hiroshima and Okayama Prefectures of western Japan and resulted a number of fatalities and serious damage to property. One of them is the Oda river basin (about $498 \mathrm{~km} 2$ ), which was severely affected by the flood during the event. Different types of observation systems were used to measure or estimate rainfall for this event. Comparison of radar and satellite-based rainfall shows a good agreement with the rain gauge observations of the entire period. Basin-mean total rainfall from Japan Meteorological Agency's analyzed radar rainfall (RADJ), Water and Disaster Management Bureau's radar rainfall (RADW), Automated Meteorological Data Acquisition System (AMeDAS), and satellite-based rainfall data (GSMaP) were about 314, 322, 357 and 304 mm during July 5-7 2018.

In this study, we applied Rainfall-Runoff-Inundation (RRI) to acquire a detailed understanding of flood processes in the Oda river basin. All the available rainfall data including different spatial resolution of hydrographic features were considered as the main input data in the model separately. Gridded flow and map of the possible maximum flood depth across the basins were generated and validated. Simulated results based on high resolution topographic data are more closely aligned with observed data. It is also found that the maximum flood inundation areas estimated by the RRI model using radar rainfall data appeared somewhat closer with the extent of flood-affected areas from the model with data of the Japanese Geospatial Information Authority (GSI) over the Mabi city. It is believed that modelled results can be used an important reference in the disaster mitigation and that they may be useful for further studies.
\end{abstract}

Keywords: Floods, torrential rainfall, RRI model, discharge, inundation.

ENGINEERING JOURNAL Volume 23 Issue 6

Received 1 April 2019

Accepted 10 June 2019

Published 30 November 2019

Online at http://www.engj.org/

DOI:10.4186/ej.2019.23.6.477

This article is based on the presentation at THA 2019 International Conference on Water Management and Climate Change toward Asia's Water-

Energy-Food Nexus and SDGs in Bangkok, Thailand, 23rd-25th January 2019. 


\section{Introduction}

Many countries of the world have been experiencing the flood each year due to torrential rainfall, which threatens loss of life and infrastructure every year. Based on a long historical data and simulation results, it is reported that the frequency of extreme rainfall and associated floods may increase in coming years [1-2]. Research also shows that the flood-vulnerable population could increase over coming years worldwide [3]. The scale and magnitude of severe flooding could be different in each region/country. Analysis of flood events, including available rainfall data, water level, discharge rate, and other hydrological processes over different type of river basins could improve our understanding on water balance as well as the proper management upcoming flood events.

In Japan, torrential rainfall cause flooding in small to medium river basins in every year. Recently, the country has recorded extreme rainfall events every year, and based on these records and the results of simulations, it seems that the number of such extreme events has increased over the last decade [1, 4-5]. One such major extreme rainfall event struck the Kanto region of Japan in September 2015. The maximum 24-hr rainfall exceeded $500 \mathrm{~mm}$ in parts of the region [6]. More recently, an extreme rain event over the Kyushu region on July 5-6 2017 yielded a maximum 48-hr rainfall exceeding $500 \mathrm{~mm}$, causing severe flooding, damage to property, and loss of life [7-8]. This year, western Japan received torrential rainfall, caused flooding in many river basins. One of them is the Oda river basin, a tributary of Takahashi river basin. It is reported that most of the downstream region (Mabi city) of the Oda river basin was flooded during the extreme evet of July 2018 (Fig. 1). Most of the city area was inundated, with floodwaters.

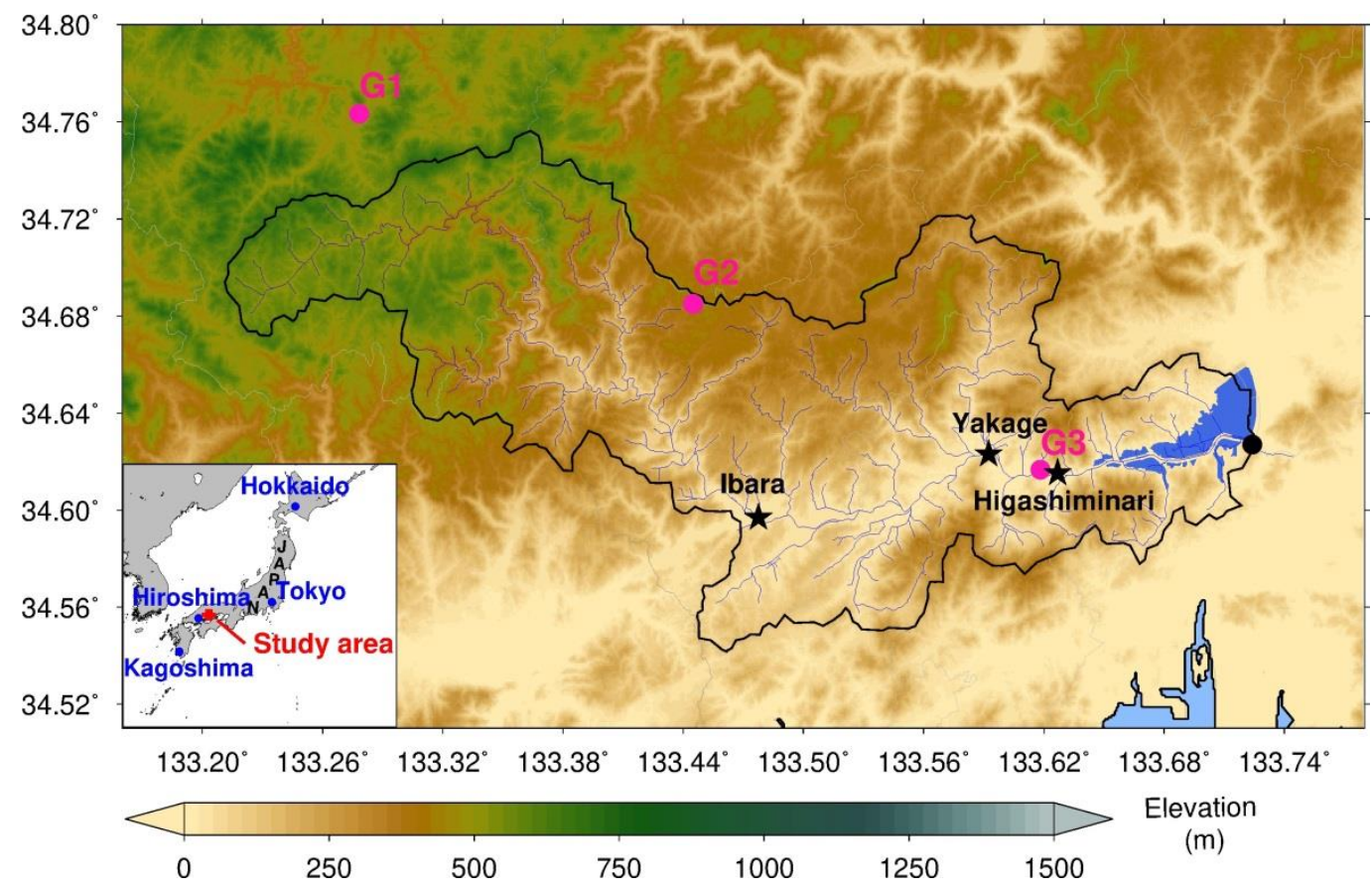

Fig. 1. Topography of the study area. Black outline and point indicates the Oada river basin and its outlet, respectively. Black stars represent hydrological stations, and the pink circles indicate AMeDAS stations. Estimated flooded area is indicated in royal blue [9].

There is a little information about the hydrological observation during the event. The gauging station Ibara, Yakage, and Higashiminami (Fig. 1) has recorded water level during the event. However, time series of those data were missing for some hours. Rainfall data collected from rain gauges have traditionally been used as inputs for hydrological modelling. The Automated Meteorological Data Acquisition System (AMeDAS) is a collection of automatic weather stations run by Japan Meteoroidal Agency (JMA) for automatic observation of surface rainfall. In Japan, estimated radar rainfall data for the whole country are available from various sources. For example, radar rainfall data from JMA, known as analyzed radar rainfall (RADJ) and the radar rainfall data from the Water and Disaster Management Bureau (RADW) under the Ministry of Land, Infrastructure, transport and Tourism (MLIT) are available. Satellite-based rainfall data, 
namely GSMaP is also available for this event. The total accumulated rainfall from the different data obtain slightly different values at each station (Fig. 2) for the period from 0000 JST 5 July 2018 to 0000 JST 8 July 2018. Each type of rainfall data has some merits and demerits for the application purpose. Discussions on quality control of those data are beyond the scope of the present study. If we are to improve our understanding of flood processes and how best to monitor them, different kinds of data must be collected. In many cases, one of that data set is used for the hydrological analysis. It is confirmed that each rainfall data set show slightly different result based on point and the basin-mean comparison analysis (Fig. 2 \& Fig. 3). An attempt is given to use all those data as the input to the hydrological analysis separately in this study. To perform hydrological analysis, Rainfall-Runoff-Inundation (RRI) model [10] is adopted. Description of the model will be given in the following section. It is believed that comparison of simulated results from different type of input data (rainfall) will be a key reference for the proper management of flood disaster within a river basin and findings of the analysis may provide a useful reference for assessing floods in other river basins during future extreme events.
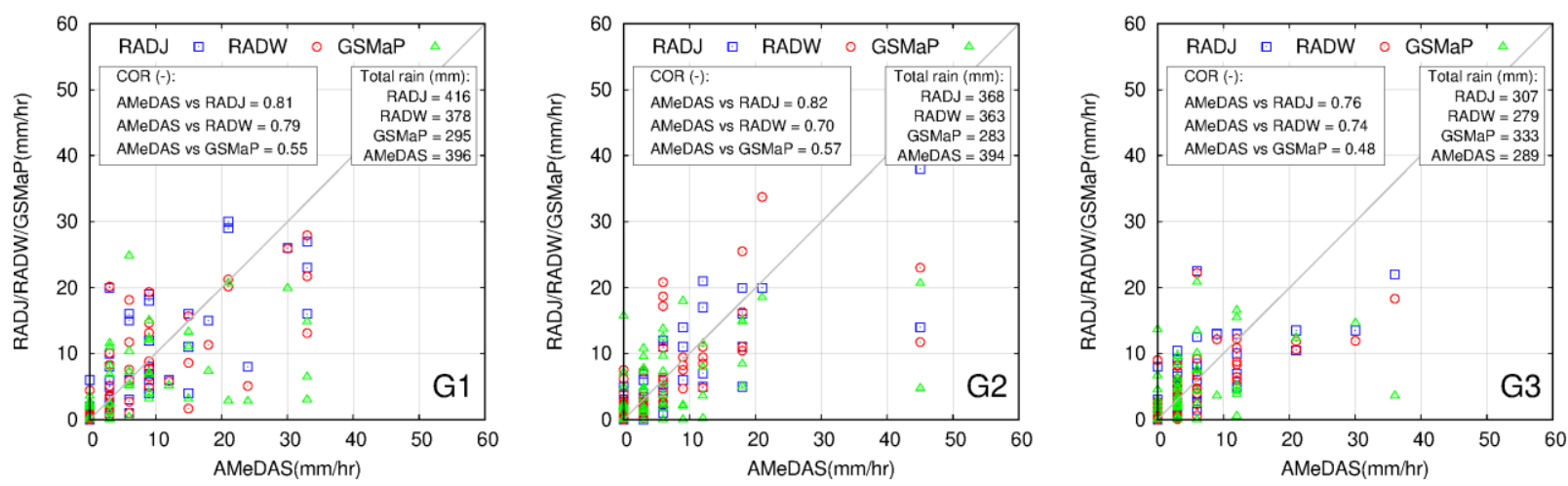

Fig. 2. Comparision of 1-hr rainfall from RADJ, RADW, GSMaP, and AMeDAS data (G1, G2 and G3 of Fig. 1) between 0000 JST 5 July 2018 to 0000 JST 8 July 2018.

\section{Overview of Rainfall Event, July 5-8, 2018}

Heavy rainfall in Japan is mainly a result of tropical cyclones, Baiu frontal activity, and local convective system. At the beginning of July 2018, western part of Japan experienced a heavy rainfall, which caused widespread disasters. Based on recorded rainfall data, the maximum total rainfall amount during the 72-hr between 0000 JST 5 July and 0000 JST 8 July 2018 was more than $300 \mathrm{~mm}$ over many places of the western Japan. Most of the rivers in the region were flooded, several people were killed, and infrastructure was extensively damaged. Our study area i.e. Oda river basin also received a high amount of rainfall during the event. The spatial and temporal variations in the rainfall associated with this event were successfully measured by the RADJ, RADW, AMeDAS, and GSMaP and the total basin-mean rainfall from them were about $314,322,357$, and $304 \mathrm{~mm}$, respectively. In general, two peaks of rainfall within the entire period can be seen around 19:00 JST 5 July and 21:00 JST 6 July in the Oda river basin. Radar rainfall data of RADJ and RADW have spatial and temporal resolution of $1-\mathrm{km}$ and $1-\mathrm{hr}$, respectively and for the GSMaP; it is 10-km and 1-hr, respectively. Total 7 AMeDAS stations within the basin were considered to represent the rainfall distribution in hourly basis. We used Thiession polygon method to interpolate the point rainfall data.

To check the consistency of each rainfall data in detail, radar and satellite-based rainfall were compared with the available rain gauge data over the basin. The locations of the rain gauges within the basin are shown by the pink circle in Fig. 1. The hourly rainfall totals from the RADJ and RADW and GSMaP were compared with the AMeDAS data (Fig. 2). The correlation values for the comparison of those stations were about $80 \%$; however, estimated rainfall data show a wider scatter for this typhoon event. It is known that typhoon events are characterized by strong wind and large variability of drop size distribution, which result in greater uncertainty when estimating rain rate from radar observations. GSMaP rainfall data looks more scatter among all data sets. If we look over the basin average rainfall comparison (Fig. 3), there is a good correlation between AMeDAS and other type of estimated rainfall data. Overall, radar-based rainfall data is in good agreement with the AMeDAS data. It should be very interesting to see the effect of those 
rain data in the hydrological simulation. Finally, all those hourly rainfall data were used as the input to the RRI model.
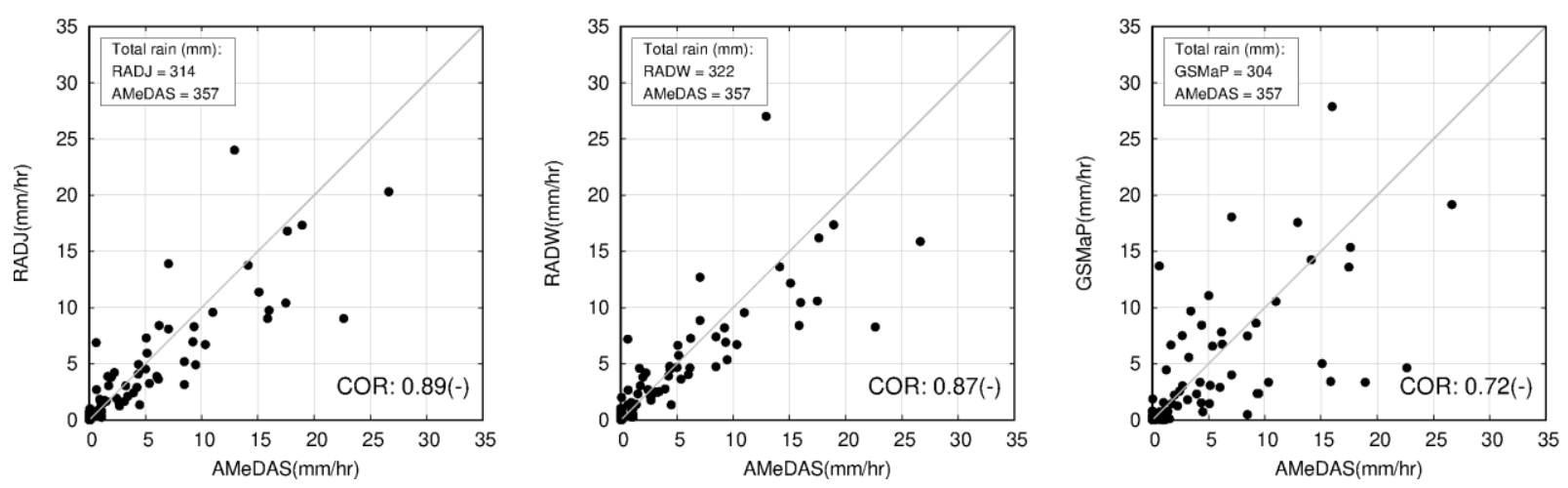

Fig. 3. Scattor plot of 1-hr average basin rainfall from RADJ, RADW, GSMaP, and AMeDAS data between 0000 JST 5 July 2018 to 0000 JST 8 July 2018.

\section{Oda River Basin Profile}

Oda river basin profile comprise approximately $498 \mathrm{~km} 2$ (based on the 3-arc sec topographic data), elevation varies from 15- $1500 \mathrm{~m}$ form mean sea level, a main tributary of Takahashi river basin. Most of the upper part of the basin is mountainous, and forest, although there is also small area of paddy fields as well as small town along the river channel. There are two rain gauges and three gauging stations over the basin (Fig. 1), from which rainfall, water level and discharge can be obtained in hourly basis. The lower part of the basin has flat topography and most of the area covers by city and paddy field. The Geospatial Information Authority of Japan (GSI) has prepared maps of the areas affected by floods [9] in the lower part of the basin after extreme events (Blue area of Fig. 1). While this mapped information is important for management purposes, it could also be used to cross-check the results from hydrological simulations.

\section{Hydrological Model}

A number of hydrological models have been developed that focus on using gridded rainfall data with high spatial and temporal resolution as input. Some of these new models are freely available for scientific research, and in this study, we used RRI model, which is a two-dimensional model, distributed-parameter, structured grid, hydrological model that simulates the hydrological response of a watershed to given hydrometeorological inputs. The model has been used in a variety of analyses and engineering studies [10, 11-12]. It may be very useful for the flood inundation analyses. The flow on the slope grid cells is calculated with the 2-D diffusive wave model, while the channel flow is calculated with the 1-D diffusive wave models.

Hydrographic information is an important input for rainfall-runoff simulations. Different spatial resolution of topographic data can be used to configure the model for the selected river basin. Theoretically, it is believed that coarse resolution of topographical resolution may increase uncertainties in the simulated results as compared with the fine resolution data set [10-12].

To understand more clearly about the role of topographic data in the rainfall-runoff simulation, we also used different resolution of topographic data to build the model. Major topographic information that used in the RRI model area are Digital Elevation Model (DEM), flow accumulation (ACC), and flow direction (DIR), which were obtained from Hydrological data and maps based on SHuttle Elevation Derivatives at multiple Scales (hydroSHEDS). In this study, we used 3-arc and 15-arc sec hydroSHEDS data to setup the model for the Oda river basin. Spatial resolutions of 3-arc and 15-arc sec hydroSHEDS data cover approximately 90 and $500 \mathrm{~m}$, respectively. After assigning the required information (DEM, ACC, and DIR) from the hydroSHEDS data to build the model, different type of rainfall data used as the input to the model separately. 


\section{Results and Discussion}

As mentioned above that different type of rainfall data (RADJ, RADW, AMeDAS, and GSMaP) and hydrographic features (DEM, ACC, and DIR) at different spatial scale were considered separately in the model simulation. It should be noted that all the required parameters other than rainfall and hydrographic features were used same in each simulation process. Basically, three outputs; river water level $(\mathrm{m})$, river discharge $(\mathrm{m} 3 / \mathrm{s})$ and inundation depth $(\mathrm{m})$ were executed form the model. In this section, simulated results of river discharge and inundation depth under the different condition is presented.

\subsection{Simulation of River Discharge}

At first, gridded simulated discharge was executed at each hour during the entire periods. Different types of rainfall data were used as the input in the model based on the 3-arc and 15-arc sec of hydroSHEDS data separately. In general, spatial distribution of river discharge is somewhat different in each case based on the 3 -arc sec hydroSHEDS data and it is tough to distinguish a clear difference quantitatively, looking such spatial distribution of river discharge for a given time step. Similar situation was obtained for the case of 15-arc sec hydroSHEDS data. Therefore, to check the performance of RRI model, we considered some available gauging station of the Oda river basin.

In this study, we considered Yakage gauging station (Fig. 1). Then, we compared our simulated results with observed or estimated data for a given gauging station. As mentioned earlier, water level data from the gauging station at the outlet are available for the event. These data have an hourly resolution and are available at the website of the water information system of the MLIT. Using these water level data, MLIT estimate discharge data at the station and post the levels on their website for public use. Unfortunately, no discharge data were reported for this year 2018 using water level data from Yakage station. Hence, we first collected the discharge and water level data for some event of data from 2012- 2016 at the station. Then, an empirical equation was fitted between water level and discharge of the collected data. The coefficient of determination $\left(\mathrm{R}^{2}\right)$ of the empirical equation was found to be approximately 1 . Next, we estimated the discharge data using the fitted empirical equation and compared the results with the discharge data simulated using the model.

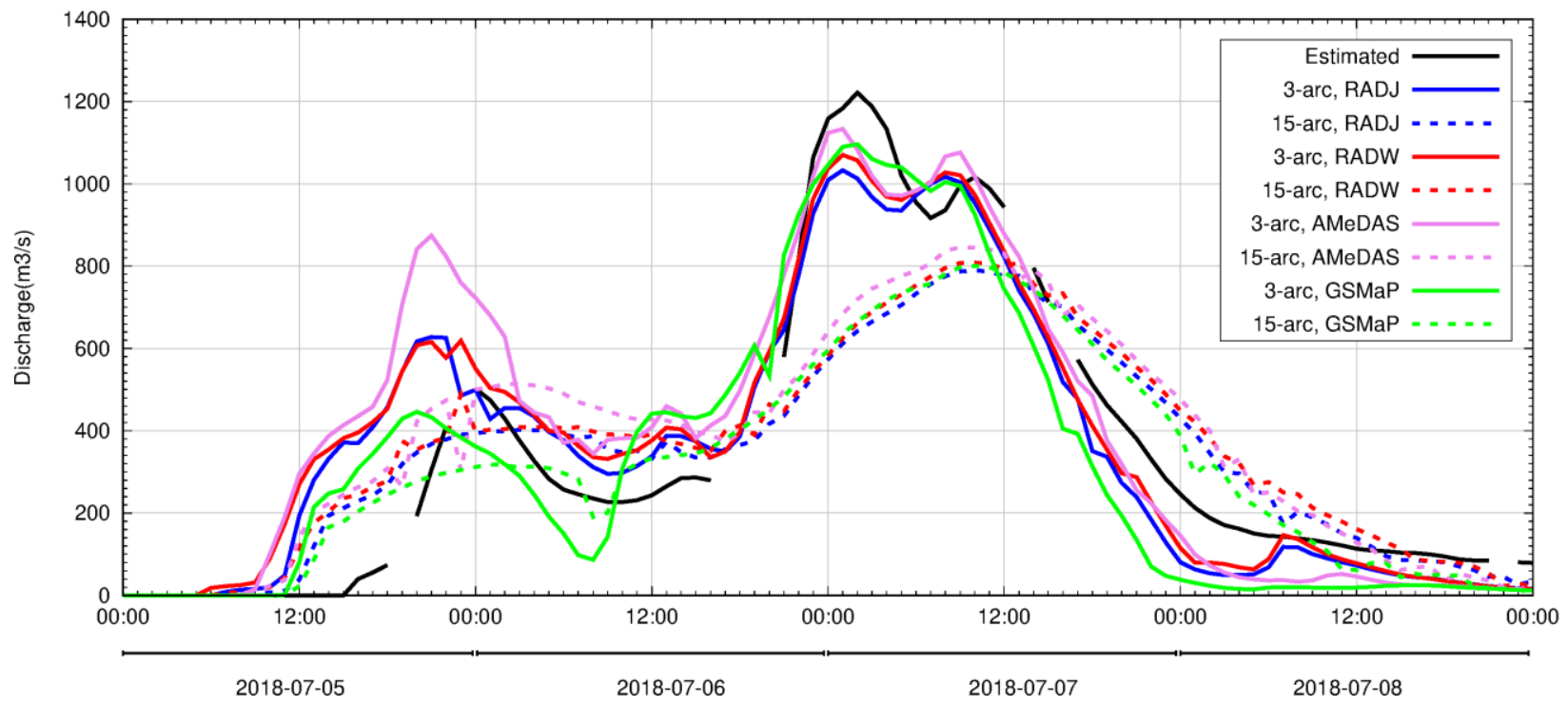

Fig. 4. Comparison of estimated and simulated river discharge at the Yakage station for the event in July 2018.

Figure 4 compares the simulated and estimated hourly river discharge at the Yakage gauging station of the basin. First, it is clearly seen that simulated discharge based on 15-arc sec hydroSHEDS data set clearly underestimate the peak discharge as compared with estimated discharge, but good agreement found between simulated and estimated discharge based on 3-arc sec hydroSHEDS data, especially for higher peaks. Simulated discharge using AMeDAS rainfall data show great fluctuation than rest of rainfall data. 
However, peak simulated discharge using all AMeDAS data in the case of 3-arc sec hydroSHEDS are close with the estimated peak discharge at this station.

Statistical parameters; Nash-Sutcliffe efficiency, and the peak difference; these had values of $0.86,-17 \%$ $0.86,-13 \% 0.83,-11 \%, 0.82,-12 \%$ for RADJ, RADW, GSMaP and AMeDAS rain data input, respectively in the case of 3-arc sec hydroSHEDS data. These values for the 15-arc sec hydroSHEDS data were 0.76, $47 \% 0.75,-45 \% 0.78,-45 \%, 0.79,-41 \%$, respectively. Overall, these statistical assessment tools indicate that the model performed reasonably well using high resolution hydrographic data (3-arc sec hydroSHEDS) for the event. One of our key interests was simulating the inundation depth all over the basin. In such case, the peak discharge could be important. As it is clear that there are some differences in peak discharge at each case, it should be interesting that how much difference results could be appeared for the inundation analysis.

\subsection{Simulation of Inundation Depth}

Estimation of inundation area over a river basin is the fundamental information that can be used in many water-related hazards studies. Therefore, simulation of flood inundation area has been emphasized in the flood disaster mitigation. Inundation depth is strongly based on the river width, embankment height and depth information. An inundation depth is calculated at each grid of the river basin. In this study, we considered default values provided in the RRI model. Embankment height is set to be $0 \mathrm{~m}$ all over the river channel of the basin.

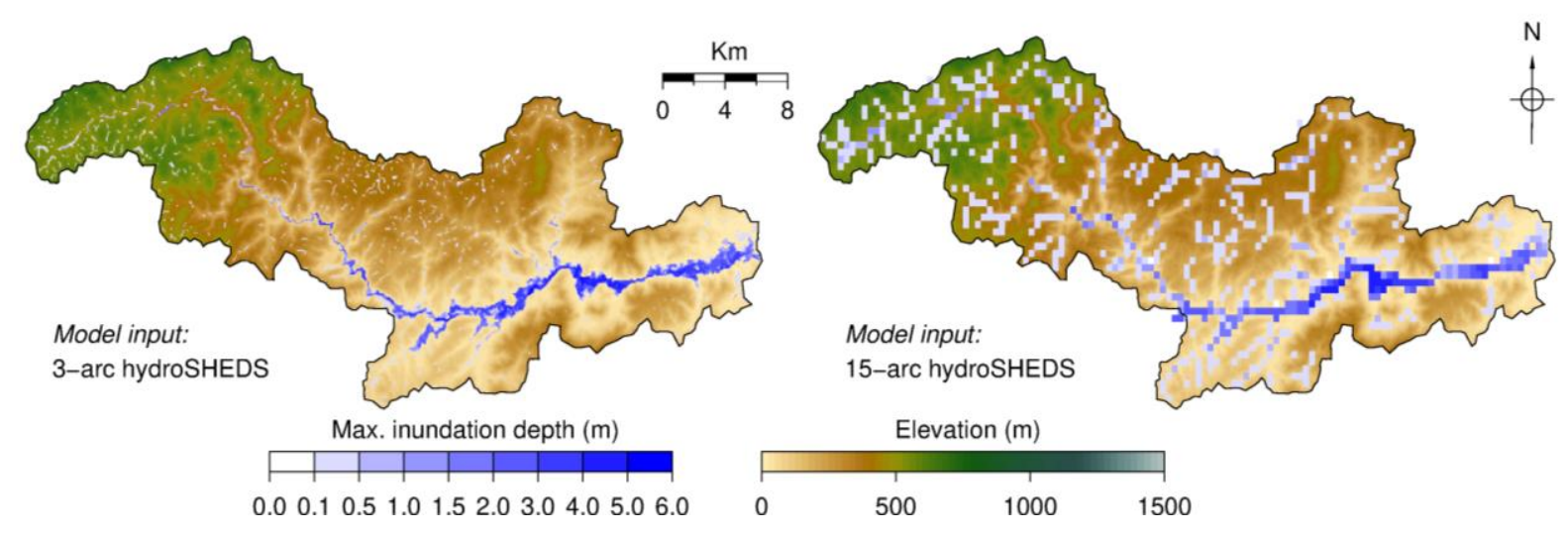

Fig. 5. Simulated maximum inundation depth for the event of 5-8 July 2018 using RADW rainfall data based on different hydrographic features.

An example of the spatial distribution of maximum inundation depths over the river basin using RADW rain data based on different scale of hydroSHEDS data is shown in Fig. 5. In general, coverage area of maximum inundation depth over the entire basin using different rainfall data looks not so different. But, inundation depth based on 3-arc and 15-arc sec hydroSHEDS data looks different each other in terms of their height and coverage area. GSI has reported inundation area over the lower part (Mabi city) of the Oda river basin (Fig. 1). Simulated results show some extent of inundation depth other part of the basin. Using RADJ, RADW, GSMaP and AMeDAS rain data as the input to the model, maximum range of inundation depth was found 5.23, 5.30, 5.52, and $5.46 \mathrm{~m}$ based on 3-arc sec hydroSHEDS data, respectively and for the 15-arc sec hydroSHEDS data, they were 4.45, 4.54, 4.52 and $4.74 \mathrm{~m}$, respectively. About $1 \mathrm{~m}$ difference found between the two sets of hydroSHEDS data. It is quite interesting that what kind of trend could happen if one uses more coarser/finer topographic data in the inundation analysis. It should be noted that simulated discharge using 3-arc sec hydroSHEDS data appeared more realistic (Fig. 3). Therefore, further analysis of inundated area derived from 15-are sec hydroSHEDS data for the Oda river basin was not shown in this study. 


\subsection{Relationship Between Modeled and Mapped (GSI) Maximum Inundation Area in Mabi City}

Now, we do not have estimated flood inundated map other than Mabi area (lower part of the basin). Hence, we compared simulated maximum inundated area and the area estimated from GSI. A GSI map of the flood-affected area was compiled from orthogonal images and survey data collected after the extreme rain event of 5-8 July 2018. We overlaid the GSI map on the modelled flood inundation map. Figure 6 shows the close comparison between the estimated and modelled maximum inundated area over the lower part of the basin. From the graphical comparison, modelled results using radar rainfall (RADJ and DWMB) are closer with the estimated flood inundated area in the Mabi city. Modelled flood inundated area can be seen other than GSI inundated area using mainly from GSMaP and AMeDAS rain data. This could be the effect of coarser resolution of rainfall data. Overall, based on this result, it can be assumed that maximum inundated area other than Mabi city is likely to be happening. Further field investigation could be a key reference to verify the modelled results.
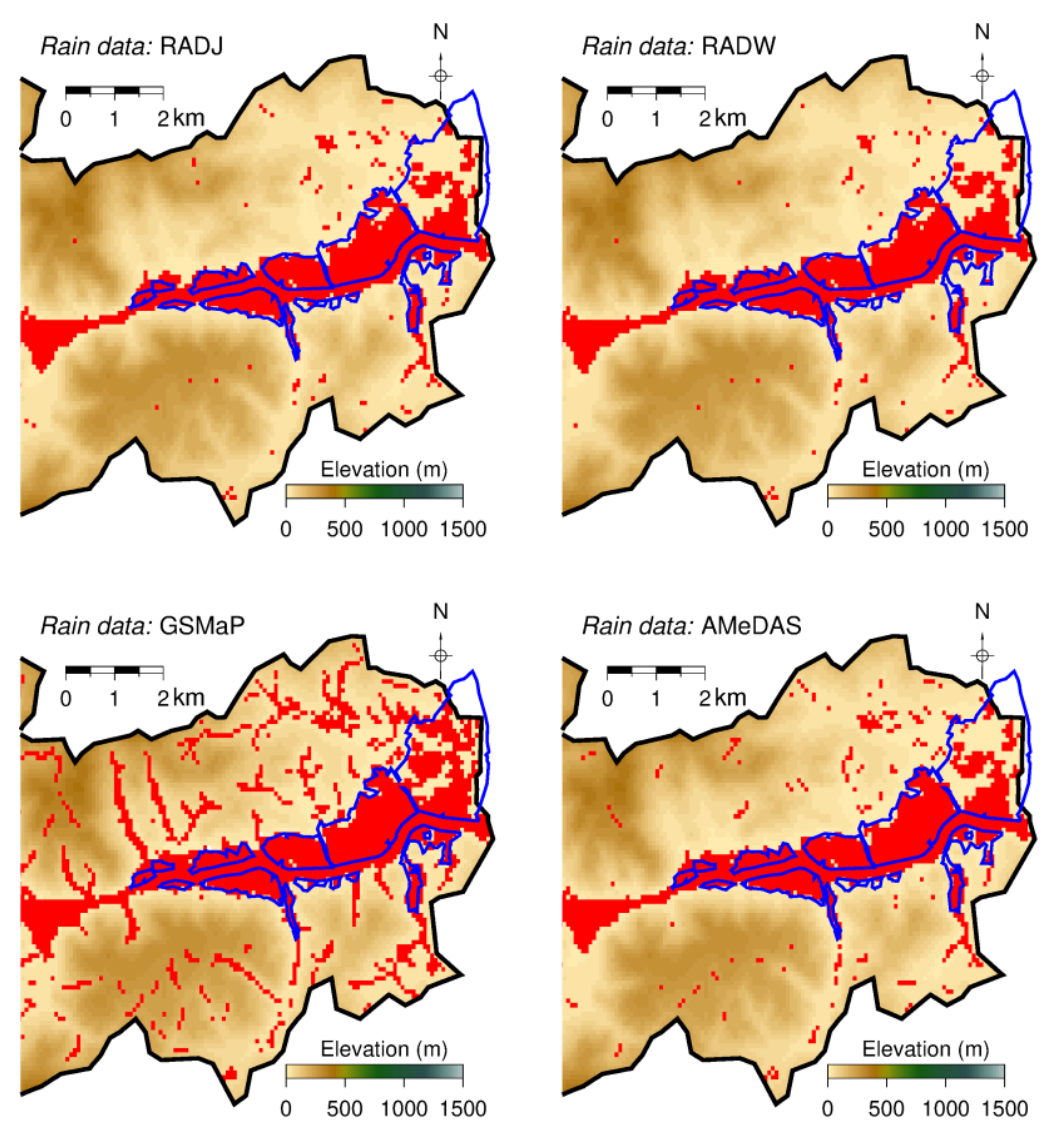

Fig. 6. Simulated inundated area (Red shades) using RADJ, RADW, AMeDAS, and GSMaP rainfall data over the lower part of the Oda river basin (Mabi area) for the event of July 2018 based on 3-arc sec hydroSHEDS data. Blue polygons indicate the estimated flood inundation area from the Geospatial Information Authority of Japan.

\section{Summary}

Hydrological simulation of the Oda river basin is performed based on the different type of rainfall data separately using different scale of topographic data to investigate the performance of the simulated results. First, we started our analysis from the comparison of available estimated and measured rainfall data set. We found that radar-based rainfall data from different source for the event of July 2018 were fairly close each other. Satellite based rainfall for this event is scattered more as compared with radar-based rainfall. It is very difficult to say that which data perform the best for this event. This is because that each data set has merits and demerits. However, we have not discussed the quality control of those data sets in this study. 
RRI model is used to perform hydrological simulation in this study. The main input data in the model were different type of rainfall data and topographic feature. Remarkable differences of simulated results were obtained based on two type of topographic features (3-arc and 15-arc sec hydroSHEDS). Moreover, simulated results clearly underestimated with the estimated data using coarser hydroSHEDS data. It should be noted that we used the same model parameters for all the cases. Hence, it may be possible that model parameters are also depend on the input scale of topographic feature and they should be tuned differently if one wants to use different topographic feature in the hydrological study. In the case of different type of rainfall data in the model, we found simulated results are close each other for this extreme event. However, some difference can be seen if we go through each time steps of the event. In general, radar-based rainfall data with $1-\mathrm{km}$ spatial resolution may have more reliable data than as of gridded data obtained from AMeDAS and GSMaP rainfall data. Finally, it can be summarized that modeled results using different type of rainfall data may be a good reference for the proper management of flood disasters in the Oda river basin.

We used default information on river features for example: embankment height, river width, and river depth in the RRI model. We changed the embankment height 1,2 , and $3 \mathrm{~m}$ for the major river channel of the basin and simulate the model separately using RADJ rainfall data based on 3-arc sec hydrographic features. Average inundation depth of $3.05,3.02,2.97$, and $2.84 \mathrm{~m}$ were modelled for the embankment height of $0,1,2$ and $3 \mathrm{~m}$, respectively. To perform inundation analysis in advance level, further improvement on these features should be necessary.

\section{Acknowledgment}

The extreme rain event of 5-8 July 2018 over western Japan caused loss of human life and high damage to property. Authors would like to express our sincere condolence to the people who have suffered from the disasters. Authors are thankful to the Ministry of Land, Infrastructure, Transport, and Tourism (MLIT), Japan Meteorological Agency (JMA), Water and Disaster Management Bureau (RADW), SHuttle Elevation Derivatives at multiple Scales (hydroSHEDS) and Geospatial Information Authority of Japan (GSI) for publishing and updating the important information and related data set.

\section{References}

[1] F. Fujibe, N. Yamazaki, and K. Kobayashi, "Long-term changes of heavy precipitation and dry weather in Japan (1901-2004)," J. Meteor. Soc. Japan, vol. 84, pp. 1033-1046, 2006.

[2] IPCC, Summary for Policy Makers, Climate Change 2014: Impacts, Adaptation, and Vulnerability. Contribution of Working Group II to the Fifth Assessment Report of the Intergovernmental Panel on Climate Change. Cambridge, UK: Cambridge University Press, 2014, pp. 1-32.

[3] Y. Hirabayashi and S. Kanae, "First estimate of the future global population at risk of flooding," Hydrological Research Letters, vol. 3, pp. 6-9, 2009.

[4] K. Inoue, "Flood disaster in Japan," J. Disaster Res., vol. 2, pp. 3-10, 2007.

[5] G. Mouri, D. Minoshima, V. Golosov, S. Chalov, S. Seto, K. Yoshimura, S. Nakamura, and T. Oki, "Probability assessment of flood and sediment disasters in Japan using the total runoff-integrating pathways model," Int. J. of Disaster Risk Reduct., vol. 3, pp. 31-43, 2013.

[6] S. P.C., R. Misumi, T. Nakatani, K. Iwanami, M. Maki, T. Maesaka, and K. Hirano, "Accuracy of quantitative precipitation estimation using operational weather radars: a case study of heavy rainfall on 9-10 September 2015 in the East Kanto region, Japan,” J. of Disaster Research, vol. 11, pp. 1003-1016, 2016.

[7] S. P.C., T. Nakatani, and R. Misumi, "Hydrological simulation of small river basin in northern Kyushu, Japan during the extreme rainfall event of July 5-6 2017," J. Disaster Res., vol. 13, pp. 396-409, 2018.

[8] S. P.C., T. Nakatani, and R. Misumi, "Analysis of flood inundation in ungauged mountainous river basins: a case study of an extreme rain event on 5-6 July 2017 in northern Kyushu, Japan," J. Disaster Res., vol. 13, pp. 860-872, 2018.

[9] Japanese Government. (2018). Map [Online]. http://maps.gsi.go.jp [Accessed September 10, 2018].

[10] T. Sayama, G. Ozawa, T. Kawakami, S. Nabesaka, and K. Fukami, "Rainfall-runoff-inundation analysis of the 2010 Pakistan flood in the Kabul river basin," Hydrological Science J., vol. 57, pp. 298-312, 2012. 
[11] S. S. Bhagabati and A. Kawasaki, "Consideration of the rainfall-runoff-inundation (RRI) model for flood mapping in a deltaic area of Myanmar," Hydrological Research Letters, vol.11, pp. 155-160, 2017.

[12] K. D. Nastiti, Y. Kim, K. Jung, and H. An, "The application of Rainfall-Runoff-Inundation (RRI) model for inundation case in upper Citarum watershed, west Java-Indonesia," Procedia Engineering, vol. 125, pp. 166-172, 2015. 